\title{
Predictors of HIV RNA Suppression on Darunavir/Ritonavir Monotherapy or Triple Therapy in the MONET and PROTEA Trials
}

Diego Ripamonti ${ }^{1}$, Andrew Hill ${ }^{*}$, Ralph DeMasi ${ }^{3}$, Ceyhun Bicer ${ }^{4}$ and Christiane Moecklinghoff ${ }^{5}$

${ }^{1}$ Infectious Diseases, A.O. Papa Giovanni XXIII, Bergamo, Italy

${ }^{2}$ St Stephens AIDS Trust, Chelsea and Westminster Hospital, London, United Kingdom

${ }^{3}$ Janssen Pharmaceuticals, Inc., Titusville, NJ, United States

${ }^{4}$ Statistics, Janssen Pharmaceuticals, Inc., Beerse, Belgium

${ }^{5} E M E A$, Janssen $\mathrm{GmBH}$, Neuss, Germany

Protease inhibitor monotherapy has been studied most intensively in clinical trials of patients with HIV RNA suppression at baseline [13]. These trials have typically enrolled patients with no prior virological failure, no co-infection with Hepatitis B, and nadir CD4 counts above 100 cells/ $\mu \mathrm{L}$. In these randomised trials, PI/r monotherapy has shown a higher risk of low level plasma HIV-1 RNA elevations; small numbers of patients taking protease inhibitor monotherapy have developed detectable HIV-1 RNA in the Cerebrospinal Fluid (CSF). However in these studies there has been no increased risk of treatment-emergent drug resistance and intensification with nucleoside analogues after initial rebound in HIV-1 RNA has led to re-suppression in most cases.

The purpose of this analysis was to investigate whether the main predictors of treatment failure during darunavir/ritonavir monotherapy. In previous studies of protease inhibitor (PI) monotherapy, patients with low nadir CD4 counts, $\mathrm{HCV}$ co-infection, poor adherence to treatment, or detectable baseline levels of HIV RNA or DNA have been the most likely to show treatment failure [4-7].

In the MONET and PROTEA trials [8,9], 529 patients with HIV RNA $<50$ copies/mL at screening switched to DRV/r 800/100 mg once daily, either as monotherapy $(\mathrm{n}=264)$ or as triple therapy with 2NRTIs $(\mathrm{n}=265)$. The two clinical trials were conducted using the same twoarm design, and used the same primary endpoint: the proportion of patients with HIV RNA suppression $<50$ copies/mL after 48 weeks of randomised treatment. The objective of this analysis was to identify the main predictors of treatment failure on DRV/r monotherapy at Week 48 in the combined MONETand PROTEA trials.

Patients with CD4 nadir $<100$ cells/ $\mu \mathrm{L}$ were excluded from the MONET and PROTEA studies. At the screening visit, patients were taking either 2 NRTIs plus either NNRTI- based or non-NNRTI based treatment (typically 2NRTI/PI or 2NRTI/Integrase).

Treatment response was defined as HIV RNA $<50$ copies $/ \mathrm{mL}$ at week 48 (FDA Snapshot method). Multivariate logistic regression was used to identify factors predictive of treatment failure in the two combined clinical trials by Week 48 . The predictors investigated were: baseline HIV RNA (below limits of assay detection), age, gender, race, HCV co-infection (based on serology), nadir CD4 count, duration of diagnosis, duration of ARV use, treatment group, baseline CD4 count and time between diagnosis of HIV and start of ART treatment. The analysis included interaction terms between the main predictors of treatment response and the effects of treatment arm.

For the univariate model, each individual factor was correlated with HIV RNA suppression $<50$ copies/mL at Week 48 (as defined above). For the final multivariate model, factors significant at the 0.10 level following stepwise selection with backward elimination procedure were retained.

In the MONET and PROTEA trials, there were 224/264 patients on $\mathrm{DRV} / \mathrm{r}$ monotherapy (85\%) with HIV RNA $<50$ copies/mL at Week 48 , versus 240/265 (91\%) on triple therapy. These trials enrolled patients from Europe, Russia and Israel. Overall, $30 \%$ of patients had CD4 nadir levels below 200 cells $/ \mu \mathrm{L} ; 19 \%$ were female, $89 \%$ were white; $49 \%$ had used an NNRTI before randomisation.

In the multivariate analysis of the PROTEA and MONET trials, there were two predictors of HIV RNA suppression at Week 48: CD4 nadir $<200$ cells $/ \mu \mathrm{L}(\mathrm{p}=0.02)$ and no prior NNRTI use $(\mathrm{p}=0.001)$. There was a trend for lower response rates overall in the DRV/r monotherapy group compared to the triple therapy group in this multivariate analysis, after adjusting for the other predictors of response $(\mathrm{p}=0.066)$ In the multivariate analysis of predictors of response, there were no statistically significant interactions between treatment group and either CD4 nadir or prior use of NNRTIs ( $\mathrm{p}=$ n.s. for each comparison). Figure 1 shows the predicted response rates for DRV/r monotherapy and triple therapy by CD4 nadir and prior use of NNRTIs, based on this multivariate analysis.

The predicted efficacy of DRV/r monotherapy ranged from $69 \%$ for those with CD4 nadir $<200$ cells $/ \mu \mathrm{L}$ and prior NNRTI treatment, to $91 \%$ for those with CD4 nadir $\geq 200$ cells $/ \mu \mathrm{L}$ and no prior NNRTI treatment. Different cut-points of CD4 nadir were evaluated, above 200 cells $/ \mu \mathrm{L}$. There was no further improvement in efficacy for patients on $\mathrm{DRV} / \mathrm{r}$ monotherapy with CD4 nadir categories above 200 cells/ $\mu \mathrm{L}$.

For the subgroup of patients who had CD4 nadir levels at least 200 cells $/ \mu \mathrm{L}$ and who had not taken NNRTIs before the trial, the observed percentage with HIV RNA $<50$ copies/mL at Week 48 was 80/88 (91\%) in the DRV/r monotherapy arm and 96/99 (97\%) in the triple therapy arm. For the subgroup of patients with CD4 nadir levels at least 200 cells $/ \mu \mathrm{L}$ and prior NNRTI treatment, the percentage with HIV RNA $<50$ copies/mL at Week 48 was $75 / 86$ (87\%) in the DRV/r monotherapy arm versus $75 / 88$ (85\%) in the triple therapy arm. For those with CD4 nadir levels below 200 cells $/ \mu \mathrm{L}$ and no prior NNRTIs, the percentage with HIV RNA $<50$ copies/mL at Week 48 was $36 / 42(86 \%)$ in the $\mathrm{DRV} / \mathrm{r}$ monotherapy and 34/37 (92\%) for triple therapy.

By contrast, for the subgroup of patients with CD4 nadir levels below

*Corresponding author: Andrew Hill, St Stephens AIDS Trust, Chelsea and Westminster Hospital, London, United Kingdom, Tel: 447834364608; E-mail: microhaart@aol.com

Received June 08, 2014; Accepted August 14, 2015; Published August 19, 2015

Citation: Ripamonti D, Hill A, DeMasi R, Bicer C, Moecklinghoff C (2015) Predictors of HIV RNA Suppression on Darunavir/Ritonavir Monotherapy or Triple Therapy in the MONET and PROTEA Trials. J AIDS Clin Res 6: 492. doi:10.4172/21556113.1000492

Copyright: (c) 2015 Ripamonti D, et al. This is an open-access article distributed under the terms of the Creative Commons Attribution License, which permits unrestricted use, distribution, and reproduction in any medium, provided the original author and source are credited. 


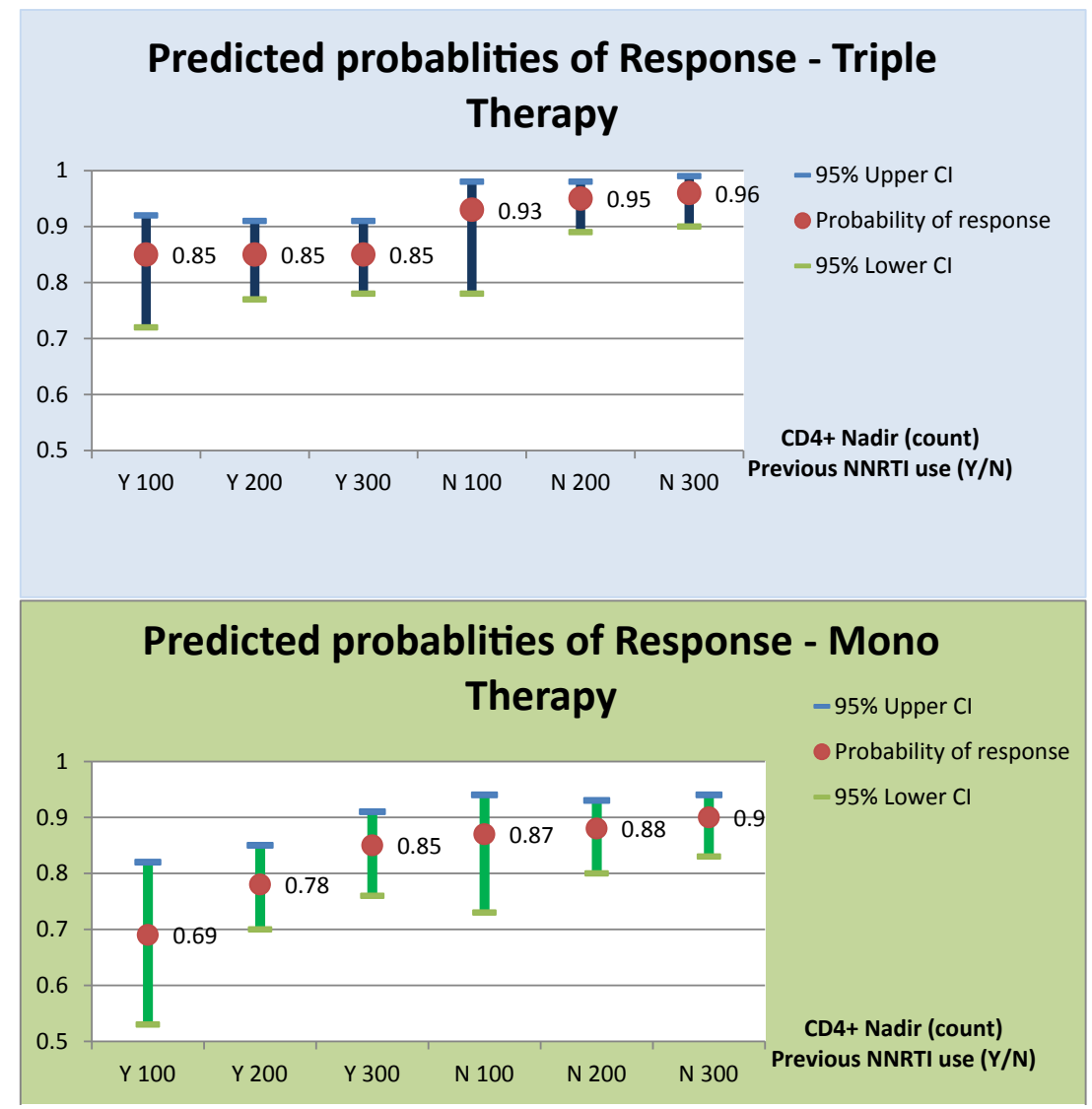

Figure 1: Predicted probability of HIV RNA suppression $<50$ copies $/ \mathrm{mL}$ at Week 48 , by nadir CD4 count and prior use of NNRTIs.

200 cells/ $\mu \mathrm{L}$ and prior NNRTI treatment, the observed percentage with HIV RNA $<50$ copies/mL at Week 48 was $33 / 48(69 \%)$ in the DRV/r monotherapy arm versus $35 / 41(85 \%)$ in the triple therapy arm.

There are several limitations to this analysis. The FDA snapshot method used in this analysis includes treatment failure as either HIV RNA elevations, or discontinuation of randomised treatment for adverse events or other reasons. This is a retrospective analysis which needs to be validated in other studies. The trial population was selected based on no prior virological failure and CD4 nadir above 100 cells $/ \mu \mathrm{L}$ - these results cannot be extrapolated to other populations. The CD4 nadir may be an indirect marker of prior disease severity. Prior NNRTI use might be a marker of the acceptability of taking a protease inhibitor during the trials.

In conclusion, this analysis suggests that patients with higher nadir CD4 counts, and those who are currently stable on boosted protease inhibitor treatment are the most likely to show sustained HIV RNA suppression during boosted protease inhibitor monotherapy. However for the group of patients with lower CD4 counts and prior use of NNRTIs, there is a clear advantage to using triple therapy. The potential benefits of using DRV/r monotherapy need to be set against the potential risk of replication of HIV RNA in the CSF - there were two cases of this in the DRV/r monotherapy arm of the PROTEA trial [9], despite no difference between the treatment arms in neurocognitive function.

An alternative to PI monotherapy could be the combination of a boosted protease inhibitor monotherapy with 3TC. Three randomised trials of this new strategy have shown promising results, with minimal toxicity and tolerability issues [10-12]. The additional cost of using 3TC in this combination would be minimal.

\section{References}

1. Arribas J, Girard PM, Paton N, Winston A, Marcelin AG, et al. (2014) Efficacy of PI monotherapy versus triple therapy for 1964 patients in 10 randomised trials. J Int AIDS Soc 17: 19788.

2. Mathis S, Khanlari B, Pulido F, Schechter M, Negredo E, et al. (2011) Effectiveness of protease inhibitor monotherapy versus combination antiretroviral maintenance therapy: a meta-analysis. PLoS One 6: e22003.

3. Paton N, Stohr W, Arenas-Pinto A, Bunn B (2014) Randomized controlled trial of a PI monotherapy switch strategy for long-term HIV management. In: CROI, Boston, US.

4. Pulido F, Pérez-Valero I, Delgado R, Arranz A, Pasquau J, et al. (2009) Risk factors for loss of virological suppression in patients receiving lopinavir/ritonavir monotherapy for maintenance of HIV suppression. Antivir Ther 14: 195-201.

5. Meynard JL, Bouteloup V, Landman R, Bonnard P, Baillat V, et al. (2010) Lopinavir/ritonavir monotherapy versus current treatment continuation for maintenance therapy of HIV-1 infection: The KALESOLO trial. J Antimicrob Chemother 65: 2436-2444.

6. Gutmann C, Cusini A, Günthard HF, Fux C, Hirschel B, et al. (2010) Randomized controlled study demonstrating failure of LPV/r monotherapy in HIV: the role of compartment and CD4-nadir. AIDS 24: 2347-2354.

7. Valantin MA, Lambert-Niclot $S$, Flandre $P$, Morand-Joubert L, Cabiè A, et al (2012) Long-term efficacy of darunavir/ritonavir monotherapy in patients with HIV-1 viral suppression: Week 96 results from the MONOI ANRS 136 study. J Antimicrob Chemother 67: 691-695.

8. Arribas JR, Clumeck N, Nelson M, Hill A, van Delft Y, et al. (2012) The 
Citation: Ripamonti D, Hill A, DeMasi R, Bicer C, Moecklinghoff C (2015) Predictors of HIV RNA Suppression on Darunavir/Ritonavir Monotherapy or Triple Therapy in the MONET and PROTEA Trials. J AIDS Clin Res 6: 492. doi:10.4172/2155-6113.1000492

MONET trial: week 144 analysis of the efficacy of darunavir/ritonavir (DRV/r) monotherapy versus DRV/r plus two nucleoside reverse transcriptase inhibitors, for patients with viral load $<50$ HIV-1 RNA copies/mL at baseline. HIV Med 13: $398-405$

9. Antinori A, Arribas J, Fehr J, Girard PM, Horban A, et al. (2014) The PROTEA trial: Darunavir/ritonavir with or without nucleoside analogues, for patients with HIV-1 RNA below 50 copies/mL. J Int AIDS Soc 17: 19525.

10. Cahn P, Andrade Villanueva J, Arribas JR, Gatell JM, Lama JR, et al. (2014) Dual therapy with lopinavir and ritonavir plus lamivudine versus triple therapy with lopinavir and ritonavir plus two nucleoside reverse transcriptase inhibitors in antiretroviral-therapy-naive adults with HIV-1 infection: 48 week results of the randomised, open label, non-inferiority GARDEL trial. Lancet Infect Dis 14 572-580.

11. Gatell J, Arribas J, Girard PM, Landman R, Pich J, et al. (2014) Non-inferiority of dual-therapy (DT) with lopinavir/ritonavir (LPV/r) plus lamivudine (3TC) vs. triple-therapy (TT) with LPV/r plus two nucleotides (NRTIs) for maintenance of HIV viral suppression: 48-week results of OLE study. World AIDS Conference, Melbourne, Australia.

12. Perez Molina J, Rubio R, Rivero A, Pasquau J, Suárez I, et al. (2014) Switching to dual therapy (atazanavir/ritonavir + lamivudine) vs. standard triple therapy (atazanavir/ritonavir+2 nucleotides) is safe and effective in virologically suppressed patients: 48-week results of a randomized clinical trial (SALT study). World AIDS Conference, Melbourne, Australia. 